eCommons@AKU

August 2013

\title{
The unseen and untold issues of clinical trials and research ethics in Pakistan.
}

Shahan Waheed

Aga Khan University, shahan.waheed@aku.edu

Emaduddin Siddiqui

Aga Khan University, emaduddin.siddiqui@aku.edu

Follow this and additional works at: https://ecommons.aku.edu/pakistan_fhs_mc_emerg_med Part of the Bioethics and Medical Ethics Commons, Clinical Trials Commons, and the $\underline{\text { Health }}$ Services Research Commons

\section{Recommended Citation}

Waheed, S., Siddiqui, E. (2013). The unseen and untold issues of clinical trials and research ethics in Pakistan.. International Journal of Medicine and Biomedical Research, 2(2), 161-162.

Available at: https://ecommons.aku.edu/pakistan_fhs_mc_emerg_med/60 
International Journal of Medicine and Biomedical Research

Volume 2 Issue 2 May - August 2013

www.ijmbr.com

(C) Michael Joanna Publications

Letter to Editor

\title{
The unseen and untold issues of clinical trials and research ethics in Pakistan
}

\author{
Waheed $\mathrm{S}^{*}$, Siddiqui $\mathrm{E}$ \\ Department of Emergency Medicine, Aga Khan University Hospital, Pakistan \\ *Corresponding author: docshahan83@hotmail.com
}

Received: 08.01.13; Accepted: 29.06.13

\begin{abstract}
Dear Editor,
Pakistan with its teeming population and economical and security setbacks cannot turn away from the escalating health issues which are important indicators for the development of a nation. Clinical research has shown tremendous growth in the past few years. The clinical trial, which is the process of evaluation of drug safety and its potential benefits ${ }^{[1]}$ is increasingly a point of interest by both multinational and national pharmaceutical companies. This business has progressed significantly in the past few years. ${ }^{[2]}$ The drug companies are making due efforts in order to gain maximum benefits from this progressing field in terms of business. ${ }^{[3]}$ This has resulted in some negativism. The three Cs of Convince, Confuse and Corrupt of Chandra Gulhati very truly project the current situation. I will go through some points which I observe, regarding the clinical trials in our country.
\end{abstract}

The patient enrollment was the first to seek attention, as the pharmaceutical companies has to enroll patients for their clinical trials; they visit the areas which have low literacy rate, low average household income and less knowledge about the rights of the study participant. The reason for this is because the companies are striving for meeting their timelines, smooth patient enrollments and low dropouts. The low literacy rate makes the individuals unable to understand the rationale of the trial and also if it does, they can easily be confused. The consent forms which if used are not explaining the core essence of the trials, and are not translated. The forms are grossly inadequate. There is a significant media and literature scarcity for the people to know about their rights. Ideally, the knowledge of the rights of an individual when registering into a clinical trial must trickle at all levels of our society if one wants to help humanity. Clinical trial is an area which still needs powerful media campaign which should focus on both the pros and cons. The individual has to be given the advantage of making decision by himself/herselfand not through the research assistants who lure them in order to gain financial benefits.

Also, the appointment of the research assistants which are mostly medical students or the young medical graduates is a major issue. They are not aware of the significance of the trials nor are they trained in terms of the International Conference on Harmonization and Good Clinical Practice Guidelines (ICH GCP guidelines). This accounts for one of the reasons of high dropout rates compared to the developed countries. The assistants must know their rights and more importantly the rights of the participants. The pharmaceutical companies must set a point of training all the individuals whom they hire as research assistants. In most cases, the research assistants are working as coordinators, clinical research associate (CRA) and monitors, which is one of the reasons of the mismanagement of the data mostly seen in studies. The saturation in the USA has resulted in the shifting of these trials to South-East Asia mainly because of the good enrollment rates due to low literacy, poverty and large population. The increasing national drug industry growth compare to the multinationals ${ }^{[4]}$ has not been good in terms of protecting the ethical rights of the individual because they are more concern for meeting their timelines and patient enrollments not paying due attention to the ethical chapter which is of pivotal importance. By formulating necessary guidelines, we can 
optimistically produce refined research assistants which will be of benefit for clinical trials and medical research.

Furthermore, there should be proper patient education before the enrollment process. They should be given time and materials which should include necessary information regarding the efficacy, side effects and adverse effects of the drug simply written in both English and Urdu. The drop out from the study is mainly due to lack of proper description of the study to participants. Soon, individuals will lose faith in the doctors and there will be no enrollments if this issue is not addressed. The need for the availability of platform for improving legal protection in particular, providing protection to test data is paramount. This is of the reason because companies invest in countries where there are laws for the protection of the study participants. A very relevant example is of Jordan which has shown increase in both research and development and also the exponential growth of the pharmaceutical industries due to the implementation of these reforms. ${ }^{[2]}$ Although there are number of trials going on in the country, we find very few full filling the standards.

Ethics is not a new chapter in our part of the world. For the past few years, it has emerged as an essential constituent for every institution carrying out research. ${ }^{[5]}$ Ethical approval is now an integral essence to have international collaborations and for obtaining funding. However, there are some impurities mixing in it as time passes. Although it has some very significant positivism after its implementation the need to safeguard it and to make a check on it is also important. To begin with, the drug companies are approaching different institutions for an easy ethical approval to get their trial started and to add on to it, there are also some incentives getting into play in this drama. This has shown some serious upsets in terms of quality. The formation of Ethical Review Boards is a very bold and a much needed step taken from our part of the world. Educating the masses, including the medical professionals must also be considered. For a start of a successful program, it must have its acceptance from the grass root level and the young graduates and medical students can provide us the necessary spice needed. Ethics must not be limited to obtaining ERC approval. It must diffuse into all aspects of the medical profession. Few institutions have their independent ethics setup which is working effectively but we find chaos at the government hospitals.

Despite these, I appreciate the efforts being taken by people at different levels for the progress of clinical trial and ethics, but there is much more which can be done and we are very optimistic that in the near future, this will improve.

\section{REFERENCES}

1. Definition adopted from www.dcri.duke.edu/patient/glossary.jsp,www.possis.co $\mathrm{m} /$ patients/glossary.php, www.wcctrials.com/glossary.HTM

2. The Clinical Trials Business, BCC Research, August 1, 2006, 231 Pages - Pub ID: WA1354481source:http://www.bccresearch.com/RepTe mplate.cfm?reportID=450\&RepDet=HLT\&cat=phm\&tar get=repdetail.cfm

3. Jafarey A. Informed consent: views from

Karachi. East Mediterr Health J 2006;12:S50-5.

4. Babar Z. Pakistan's pharmaceutical industry. The Dawn, June 17th, 2005.

5. Hyder AA, Nadeem S. Health ethics in

Pakistan: a literature review of its present state. J

Health Popul Nutr 2001;19:6-11.

doi: http://dx.doi.org/10.14194/ijmbr.2211

How to cite this article: Waheed $S$, Siddiqui $\mathrm{E}$. The unseen and untold issues of clinical trials and research ethics in Pakistan. Int $\mathrm{J}$ Med Biomed Res 2013;2(2):161-162

Conflict of Interest: None declared

\section{cc) (i) (2) (2)}

EY NC SA This is an Open Access article distributed under the terms of the Creative Commons Attribution 3.0 License (http://creativecommons.org/licenses/by-nc-sa/3.0/) which permits unrestricted, non-commercial, share-alike use, distribution, and reproduction in any medium, provided the original work is properly cited. 